\title{
Bathymetry: Features and Hypsography
}

\author{
Heidi M. Dierssen \\ Department of Marine Sciences/Geography, University of Connecticut, Groton, Connecticut, U.S.A. \\ Department of Biology, Norwegian University of Science and Technology, Trondheim, Norway
}

Albert E. Theberge, Jr.

Captain, NOAA Corps, NOAA Central Library, Silver Spring, Maryland, U.S.A.

\begin{abstract}
The study of the distribution of elevations on the Earth or hypsography shows how more than half of the world ocean is dominated by deep basins $(4-6.5 \mathrm{~km})$ covered with abyssal plains and hills. Seafloor from 2 to $4 \mathrm{~km}$ depth is primarily comprised of oceanic ridge systems that spread over $\sim 30 \%$ of the seafloor. The shallow seas and continental margins from sea level to $2 \mathrm{~km}$ depth cover the least amount of area and represent only $\sim 15 \%$ of the seafloor. Superimposed on the primary features of the seafloor landscape are secondary features such as the median valley, seamounts, and submarine canyons. Finescale geomorphology of the underwater landscape and discontinuities in bathymetry are increasingly being used to assess distributions of marine organisms. New terminology and computational methods identify seafloor features that enhance marine biodiversity and allow for better management of vulnerable marine ecosystems.
\end{abstract}

\section{INTRODUCTION}

Up until the mid-20 th century, the seafloor was thought to be featureless consisting of bits of rock and sediment eroded from the continents and flushed into the ocean reservoirs. ${ }^{[1]}$ However, we now know that ocean bathymetry encompasses a varied seascape including vast mountain ranges, deep trenches, fracture zones extending for thousands of miles, the flattest plains on Earth, and a plethora of lesser meso- and microscale features ranging from individual seamounts to individual ripples and tidal channels. Comprehension of this landscape is a key component of the theory of plate tectonics, an intrinsic part of marine ecology, and a significant component of ocean circulation on global scales to individual estuaries. Indeed bathymetry and ocean science are intricately intertwined and one cannot be understood without the other.

Hypsography is the study of the distribution of bathymetric features across the Earth's surface and provides the percentage of the seafloor covered by large-scale features, such as continental shelves and abyssal plains. Fine-scale oceanic features can also be mapped at high resolution using new technology. ${ }^{[2]}$ Assessing the geomorphology or shape of underwater landforms is now an important component in developing marine reserves to protect sensitive marine ecosystems. Many organisms aggregate at discontinuities in the bathymetry that can also affect local eddies and current features that shape aspects of local water properties. Bathymetry of coastal estuaries and bays must also be evaluated in terms of tidal currents driven by the gravitational influence of the moon that can change bathymetry on hourly time scales. In a little over a century, the vast underwater landscapes from large- to small-scale features have been revealed, and this knowledge has contributed to the fundamental understanding of the Earth's processes.

\section{BATHYMETRIC FEATURES AND HYPSOGRAPHY}

The large-scale primary and secondary features of the deep seafloor and fine-scale features on the marine and coastal seafloor are discussed further.

\section{Large-Scale Features}

Covering $3.6 \times 10^{8} \mathrm{~km}^{2}$, or $71 \%$ of the Earth's surface, the oceanic basins are dominated by three major physiographic features: 1) deep basins covered with abyssal plains and hills covering $~ 53 \%$ of the seafloor; 2 ) the world-girdling oceanic ridge system covering $~ 31 \%$ of the seafloor; and 3 ) continental margins and shallow seas comprised of 
continental shelf, slope and rise covering over $16 \%$ of the seafloor (Fig. 1). Undulating abyssal hills and gently sloping to flat abyssal plains lying between 4 and $6.5 \mathrm{~km}$ spread across the vast ocean floor. Very large features of significant lineal extent include the great trenches and fracture zones of the world ocean that can extend for thousands of miles either along the margins of ocean basins as in the case of trenches or across ocean basins as in the case of fracture zones. The ridges and rises associated with fractures zones predominantly occur at depths from 2 to $4 \mathrm{~km}$ across the world ocean (Fig. 1). Oceanic trenches from 6.5 to $\sim 11 \mathrm{~km}$ in depth cover $0.2 \%$ of the world ocean. Continental margins are made up of continental shelves, continental slopes, and continental rises. Continental shelves border the continents and vary in size and shape across the world ocean. Comprised of continental crust, they are relatively flat containing thick layers of terrigenous sediments from riverine input. The widest continental shelves tend to occur along passive margins where considerable sediment can build up over time. In active continental margins with converging plates, there can be little to no shelf at all. The depth limit describing the continental shelf is often considered to be $<200 \mathrm{~m}$, but deeper shelves extending to $500 \mathrm{~m}$ commonly occur in polar regions north and south of $60^{\circ}$ latitude including Antarctica and Greenland. The shelf break indicates the point where the continental shelf abruptly ends and the slope steepens dramatically in what is referred to as the continental slope. At the base of the slope, the continental rise is characterized by a gentle slope of accumulated sediment that merges into the abyssal plain on passive continental margins.

Superimposed on the primary features of the seafloor landscape are secondary features such as the median valley associated with the mid-ocean ridge system, mountain ranges, and ridges not associated with the mid-ocean ridge system. The abyssal hills and plains are interrupted by a spectrum of larger hills, knolls, and cones with varying elevations culminating with the higher underwater mountains having relief $>1000 \mathrm{~m}$ called seamounts. With over 100,000 estimated to occur on the seafloor, seamounts are typically formed from volcanic activity in association with diverging plates, hot spots, or converging plates.
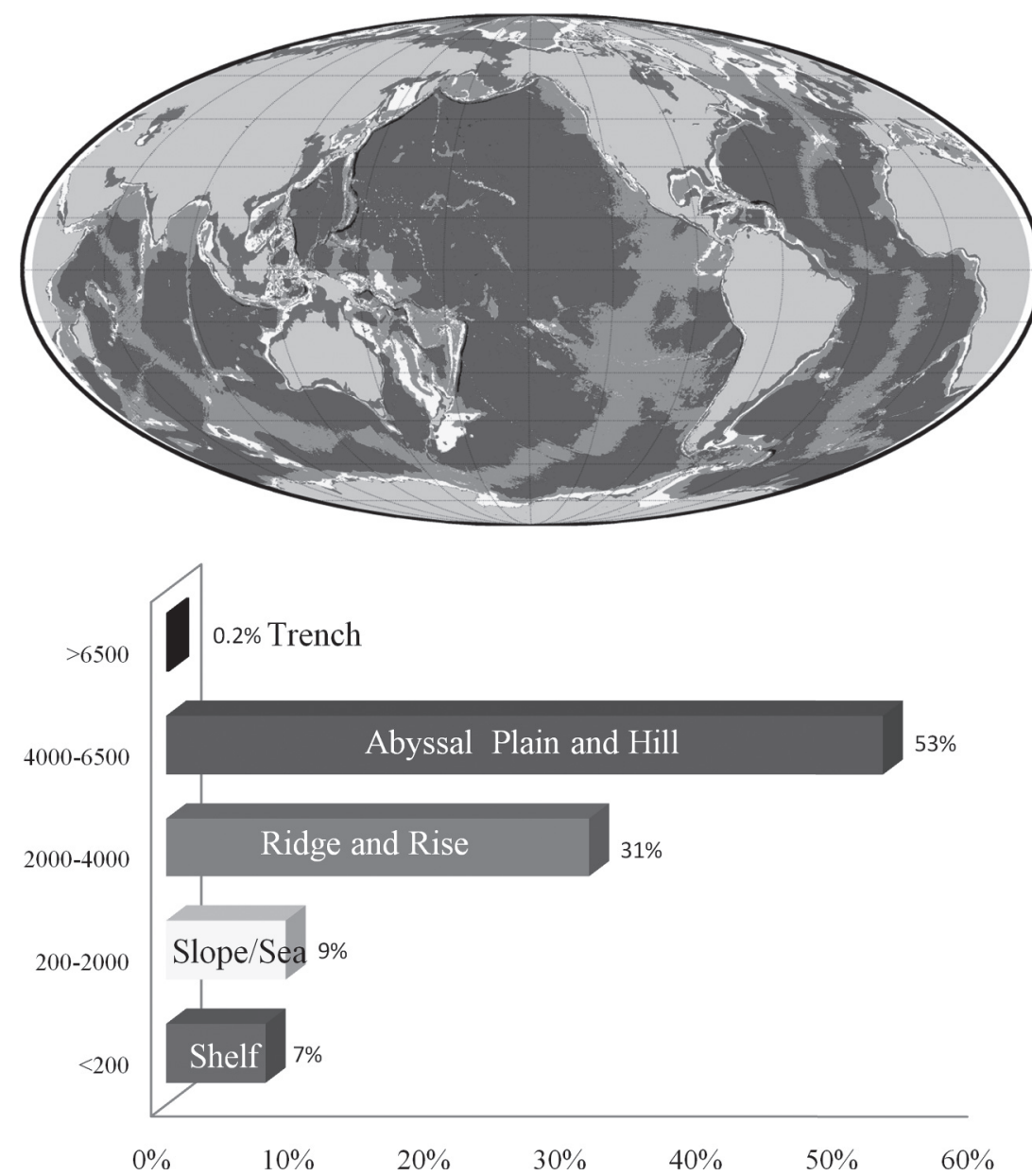
Tablemounts or guyots are flat-topped seamounts formed by wave erosion which has been transported to deeper water and submerged on a moving plate. Volcanic activity forming mountains (either undersea or continental) commonly occurs on the back side of the trench feature where the downthrust subducting plate heats and melts. Volcanic island arcs are formed in this manner and run parallel to a trench at a distance of $\sim 200 \mathrm{~km}$ from the trench axis. Submarine canyons, generally extensions of large rivers or formed by turbidity flows, periodically cut through the continental slope and transport considerable sediments from the shelf to the deep sea. Other secondary features include individual basins, troughs, deeps, holes, escarpments, benches, terraces, regional and local plains, great canyons, and lesser valleys found on the continental slopes of the world.

Virtually all of the primary and many of the secondary features of the world ocean were discovered by either line and sinker technology or by single-beam echo sounding. ${ }^{[1]}$ However, because the introduction of multibeam sounding systems coupled with the global positioning system, ${ }^{[2]}$ many additional deep-sea features have been discovered including hydrothermal vents and vent fields, mud volcanoes, mud wave and dune fields, individual lava flows, landslide scars, and diapiric structures including commercially valuable salt domes.

Comprehension of the significance and inter-relationships of the primary and secondary features of the seafloor has come about only since the formulation of the theory of plate tectonics. Plate tectonics describes the surface of the Earth in terms of numerous plates that either move away from each other at divergent plate boundaries, collide at convergent plate boundaries, or slide past each other along great faults known as transform faults. The median valleys of mid-oceanic ridges are the primary location of divergent boundaries, also known as seafloor spreading centers, where new seafloor is being produced from upwelling magma. Sites where plates collide with one plate being thrust under another consuming the seafloor, known as subduction zones, are marked by the great oceanic trenches, while colliding plates with no subduction form the great terrestrial mountain ranges of the world such as the AlpineHimalayan belt of Europe and Asia. Sites where plates slide past one another are marked primarily by the numerous offsets on the mid-oceanic ridge system and are known as transform faults or fracture zones.

The presence of the abyssal plains and hills can also be explained from tectonic processes in combination with sedimentary processes. As new seafloor is formed and then pushed away from the median valley, parallel trains of abyssal hills are formed. With the passage of time, these hills are draped with sediment. When completely covered, the resulting surfaces are termed abyssal plains. Lineal chains of islands and seamounts can also be formed over long-lived stationary "hot spots" that provide conduits for magma to come to the surface. As the seafloor moves over these hot spots, lineal chains of islands and seamounts are formed trending in the direction of seafloor motion. The Hawaiian Islands and Emperor Seamount chains are examples of this phenomenon.

\section{Fine-Scale Features}

Marine geomorphology-the study of underwater landforms - is becoming an important component of management of marine ecosystems. Increasingly, the fine-scale ridges and troughs of the underwater landscape are being used to assess and define biological habitats for fish and other marine organisms. In Long Island Sound (Fig. 2A), the largest urban estuary in the United States, a concentrated mapping program has characterized the physical character of the seafloor using multibeam sonar for depth and "sidescan" sonar for a qualitative view of seafloor reflectivity characteristics. ${ }^{[3]}$ Such high-resolution images showing sand ripples, uplifted ridges, and small depressions in bathymetry (Fig. 2B) are valuable for assessing benthic habitats, current modeling, and evaluating sedimentary processes.

Many species aggregate at locations with particular geomorphic features, such as reef promontories, uplifted ridges, and shelf edges, that are associated with abrupt discontinuities in surrounding structure. ${ }^{[4]}$ When related to the seafloor, the terms "habitat heterogeneity" and "keystone structures" are applied to seafloor features that may enhance biodiversity by providing refugia from predation, enhanced or alternative food resources, spawning areas, stress gradients and substratum diversity. ${ }^{[5,6]}$ Not only do undersea landforms provide three-dimensional structure, but they can also influence eddies and currents and create oceanographic conditions important for the growth and survival of marine communities. ${ }^{[7]}$ Submarine canyons, for example, are sites of organic enrichment and benthic productivity due to sinking of particulate materials from the shores. ${ }^{[5]}$

Modern techniques allow for mapping of the seafloor with higher precision than ever before and assessment of benthic structures at meter scales or less. Because of linkages between bathymetric features, biodiversity, and biogeochemistry, new methods for classifying the seafloor have been developed. A benthic location can be classified according to a terrain ruggedness index ${ }^{[8]}$ or more specifically the bathymetric position index (BPI), for example, which identifies the sloping nature of a region or "neighborhood." A positive BPI denotes ridge features; zero values indicate flat terrain or region with a constant slope; and negative values correspond to valleys. Bathymetric data tends to be spatially autocorrelated where locations closer together are more related than those further apart, and thereby the value of the BPI is related to the scale of data under investigation and the type of topography within the selected region. ${ }^{[9]}$ Often BPIs are estimated at different scales to define different scales of features from small sand ripples to large-seascape features such as channels. 


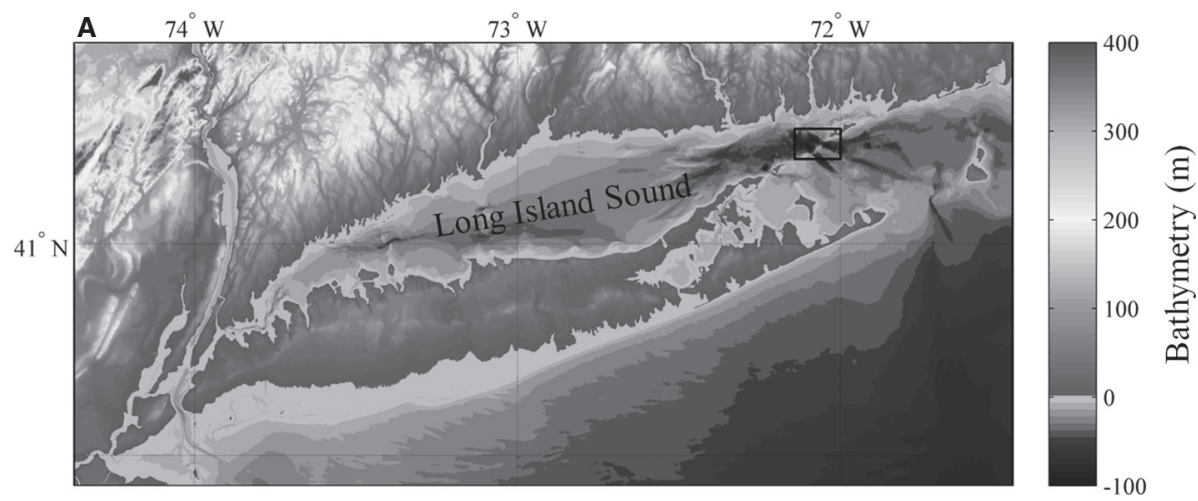

B

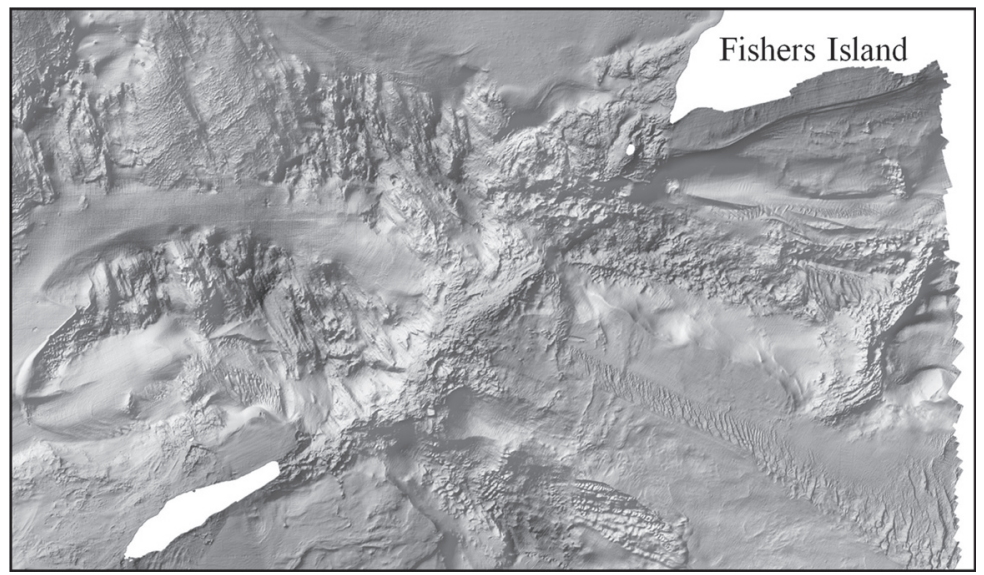

Fig. 2 (A) Bathymetry of Long Island Sound, the United States as mapped from NOAA digital high-resolution coastal gridded data (Amante ${ }^{[14]}$ ). (B) High-resolution bathymetry from multibeam sonar of the area around Fishers Island, outlined in black in Panel A, highlights a variety of detailed seafloor features (Poppe and Polloni ${ }^{[3]}$ ).

Source: Image courtesy of Long Island Sound Resource Center.

Fine-scale benthic features are also characterized by their "rugosity," which is a measure of the bottom complexity or "bumpiness." It is often parameterized as the surface area in relations to the planar area. A rugosity of 1 indicates a smooth, flat surface and values $>1$ indicate higher relief. Regions with higher rugosity have been linked to higher biodiversity. ${ }^{[10]}$

Ongoing efforts are underway to organize and define coastal and marine environments in meaningful units that can be compared across different temporal and spatial scales. The Coastal and Marine Ecological Classification Standard (CMECS) is one such effort that defines a habitat using five different components: water column, benthic biotic, surface geology, sub-benthic, and geoform component ${ }^{[11]}$ (Fig. 3A). The geoform component classifies the major geomorphic or structural characteristics of the seafloor and is often assessed with bathymetric data. The classifiers tend from large- to small scale and begin with coastal region, physiographic setting, geoform (natural), and subform, with an additional category called geoform (anthropogenic). The physiographic setting is defined from many of the primary oceanic features described earlier (e.g., mid-ocean ridge, abyssal plain, etc.) and also includes the "coast" defined as the land-water interface. Geoform classifies features from centimeter to kilometer scale and has been separated into structures that are natural and anthropogenic in origin. Anthropogenic geoforms cover jetties, piers, artificial reefs, and other man-made structures and seafloor areas where human activities have changed the landscape (e.g., trawling and prop scars). Within the natural geoforms are definitions to describe marine features (e.g., seamounts, guyots, banks, boulder fields, and megaripples) and those structures in coastal regimes (e.g., fjord, beach, delta, coral reef, and lagoon). Finally, the subform category describes smaller features within the geoform and can include walls, escarpments, and also such factors as substrate orientation which can impact the availability of light and wave energy. Hence, many layers of complexity are required to describe the bottom topography itself, not to mention the additional components describing the type of substrate and biota associated with these features.

In a reef system, these techniques can be used to define zones corresponding to the geomorphology of the coral reef community. A recent analysis mapped the reef structures according to the following categories: shoreline intertidal, 
A

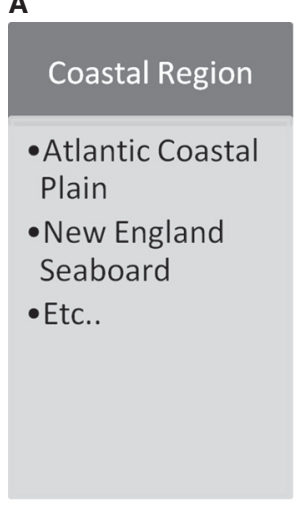

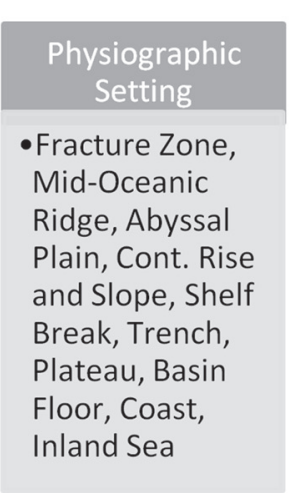

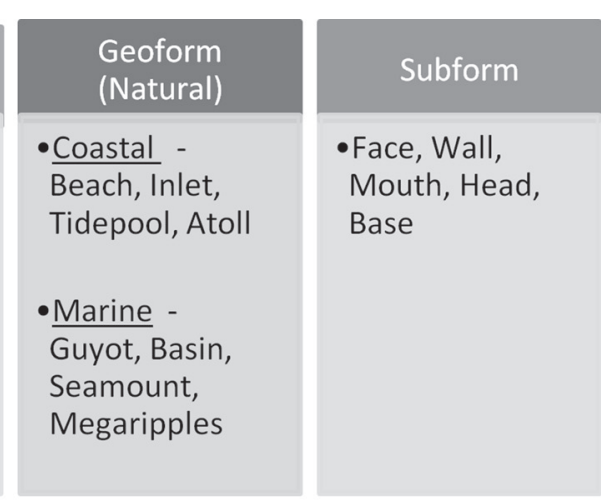

\section{B}

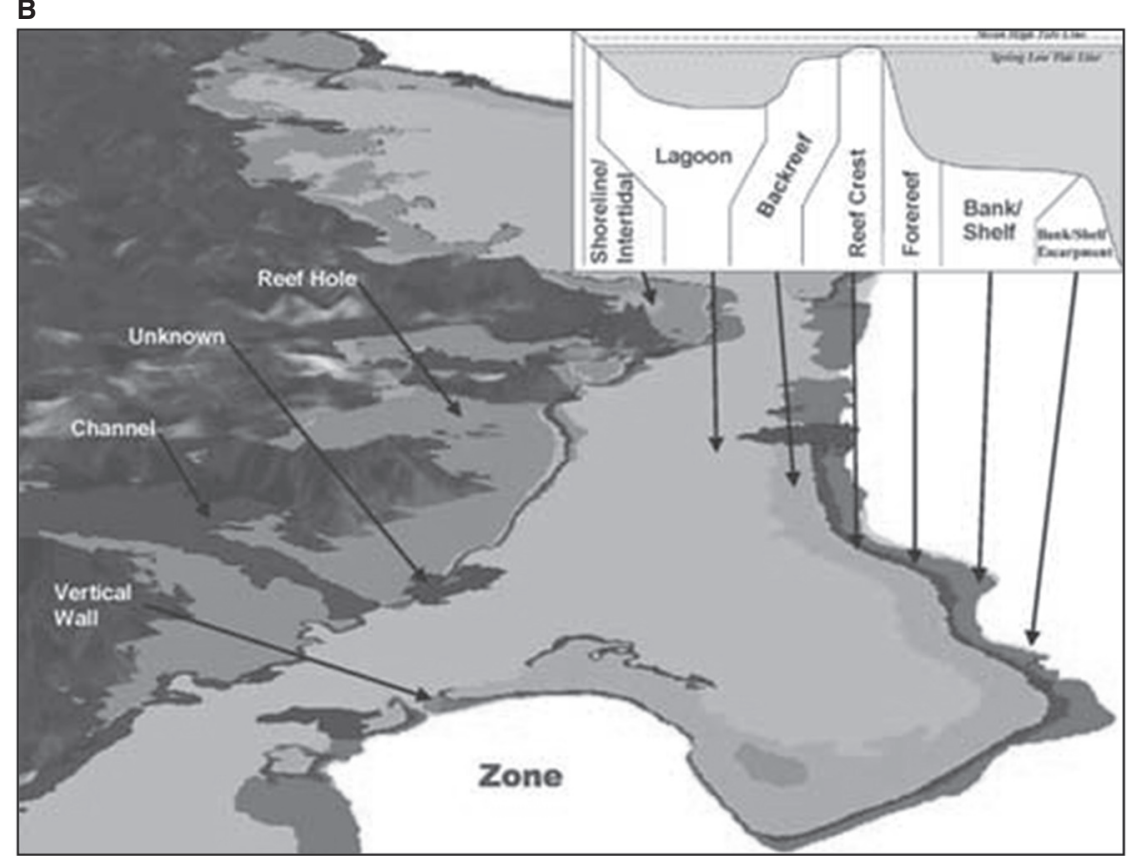

Fig. 3 (A) Geomorphologic classification scheme proposed by the Coastal and Marine Ecological Classification Standard (CMECS) categorize features from large (coastal region) to small (subform) spatial scales. (B) A classification of a coral reef demonstrating the different bathymetric features mapped from a bathymetric grid (Battista $\left.{ }^{[12]}\right)$.

Source: Image from NOAA, NOS, NCCOS Biogeography Branch. ${ }^{[12]}$

vertical wall, lagoon, back reef, reef flat, reef crest, fore reef, bank/shelf, bank/shelf escarpment, channel, and dredged area ${ }^{[12]}$ (Fig. 3B). These geomorphologic zones can be comprised of different benthic substrate or cover types. The "lagoon," for example, may be covered by patch reefs, sand, and seagrass beds. Integrating and assessing the biota and geomorphology is important for managing these sensitive coastal resources.

\section{HYPSOGRAPHY OF THE OCEAN}

The bathymetry of each of the five ocean basins varies considerably (Fig. 4). Ridges and rises associated with seafloor spreading can be found in all five of the ocean basins. As mapped in the $1800 \mathrm{~s},{ }^{[1]}$ the Mid-Atlantic Ridge extends from the north of Iceland to the Southern Ocean boundary. Wide continental shelves ( $<200 \mathrm{~m}$ depth) are visible along much of the western Atlantic Ocean. The vast Pacific Ocean contains mostly broad expanses of deep ocean floor including abyssal hills, chains of seamounts, and lineal scars of great fracture zones. Prominent bathymetric features also occur along the margins of the Pacific Ocean. The Pacific Ocean is bounded by the "Ring of Fire" consisting primarily of subducting plates on the western, northern, and eastern margins with deep trenches and considerable earthquakes and volcanic activity. The southern boundary is defined by the Pacific-Antarctic Ridge and the southern portion of the East Pacific Rise. The Indian Ocean is crossed by ridges and volcanic island structures where the African, Indian, Australian, and Antarctic crustal plates all converge. With the exception of Western Australia, the Indian Ocean has 


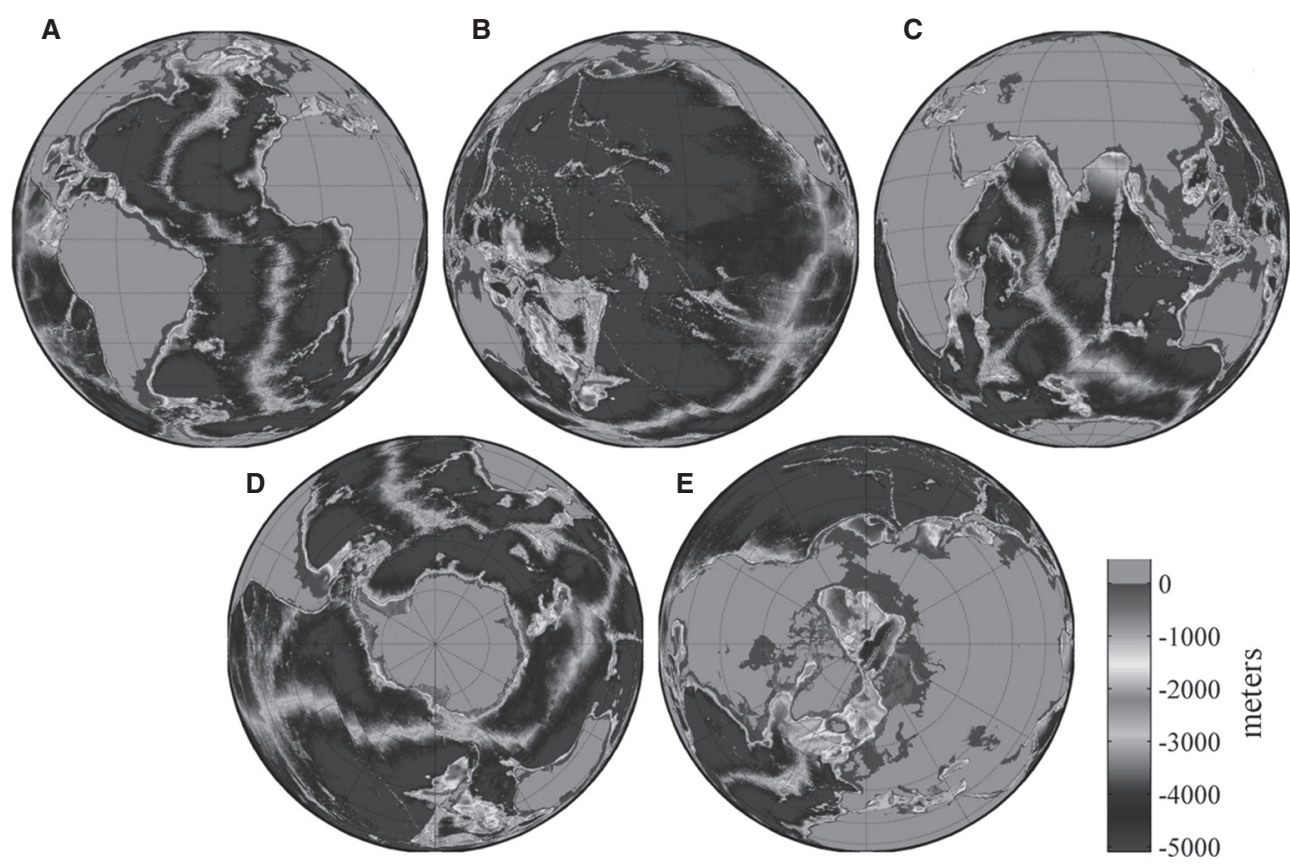

Fig. 4 Gridded bathymetric data are a compilation of satellite gravimetric data and sonar data from throughout the global ocean. ${ }^{[14]}$ These plots show bathymetry (m) for each ocean basin in orthographic projection: (A) Atlantic, (B) Pacific, (C) Indian, (D) Southern, and (E) Arctic. Land surfaces are shown in gray.

limited continental shelf area. In contrast, the Arctic Ocean represents the shallowest of ocean basins and is characterized by broad expansive deep $(500 \mathrm{~m})$ shelves and shallow seas. The Southern Ocean also contains deep continental shelves $(500 \mathrm{~m})$, large expanses of abyssal plains, and prominent ridge features bordering the Pacific, Atlantic, and Indian Oceans.

Taken from the Greek word "hypsos," meaning height, hypsography is the study of the distribution of elevations on Earth and is used to relate bathymetry to the projected two-dimensional surface area of a region or feature. The "hypsographic curve" of Earth shows the cumulative percentage of the Earth surface area at different elevations from above and below sea level (Fig. 5). As shown, the ocean represents $\sim 71 \%$ of the Earth's surface and most of this surface area is quite deeply submerged at close to 4 $\mathrm{km}$ below sea level. Based on our current and still limited knowledge of bathymetry, the average depth of the oceans is calculated to be $3.7 \mathrm{~km}$. The prevalence of deep seafloor is related to the heavier elemental composition of oceanic crust that makes it much denser than terrestrial crust. Along the perimeters of the ocean basins, the ocean slopes rapidly and very little of the Earth's surface occurs between the continental shelves $(<500 \mathrm{~m})$ and the deep sea $(4 \mathrm{~km})$. Metaphorically, the ocean basins can be considered like deep bowls with thin rims and steep sides. However, the bowl bottoms are not smooth, but littered with abyssal hills and seamounts, as well as spreading ridges that appear as jagged seams laced across a baseball.

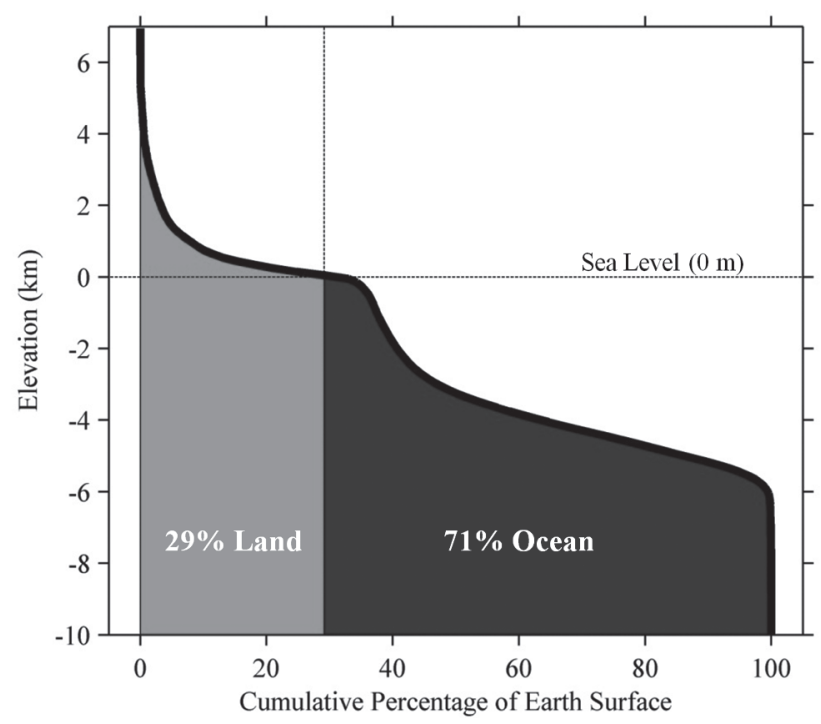

Fig. 5 Hypsographic curve modeled from ETOPO1 gridded bathymetric data ${ }^{[14]}$ shows the cumulative percentage of Earth's surfaces above and below sea level. Land represents a smaller depth range and comprises 29\% of Earth's surface; whereas, ocean has nearly an $11 \mathrm{~km}$ depth range and covers $71 \%$ of the Earth's surface. Over $50 \%$ of Earth falls between 4 and $6 \mathrm{~km}$ below sea level comprised predominantly of abyssal plains and hills.

\section{CONCLUSION}

Representing less than a third of the Earth's surface, the land is dwarfed by the enormity of ocean. The ocean has more relief with deep $11 \mathrm{~km}$ trenches compared to 
maximum peaks of $7 \mathrm{~km}$ on land. The large-scale features of the underwater landscape span the five ocean basins from the Southern Ocean northward to the Arctic Ocean. Describing and classifying coastal and marine geomorphology at fine scales is still an area of active research that requires more data and enhanced computational methods. Bathymetry is not static and the percentage of ocean is likely to increase in the next century as sea-level rises due to thermal expansion of ocean water and melting of landbased glaciers. ${ }^{[13]}$ Ocean bathymetry will need to be revised particularly in the near-shore environment as the oceans get deeper and coastal regions become submerged. While islands and seamounts are continually being formed by volcanic activity, many islands will become submerged by tectonic activity and projected sea-level rise.

\section{ACKNOWLEDGMENTS}

Funding was provided from the U.S. Office of Naval Research, U.S. National Aeronautics and Space Administration (Dierssen), and U.S. National Oceanographic and Atmospheric Association (Theberge).

\section{REFERENCES}

1. Dierssen, H.M.; Theberge, A.E. Bathymetry: History of seafloor mapping. In Encyclopedia of Ocean Sciences; Taylor and Francis: New York, NY, 2012; 360 pp.

2. Dierssen, H.M.; Theberge, A.E. Bathymetry: Assessing methods. In Encyclopedia of Ocean Sciences; Taylor and Francis: New York, NY, 2012; 360 pp.

3. Poppe, L.; Polloni, C. Long Island Sound Environmental Studies. US Geol. Surv. Open File Rep. 1998, 98, 1.

4. Heyman, W.D.; Wright, D.J. Marine Geomorphology in the Design of Marine Reserve Networks. Prof. Geogr. 2011, 63, 429-442.
5. Vetter, E.W.; Smith, C.R.; De Leo, F.C. Hawaiian hotspots: enhanced megafaunal abundance and diversity in submarine canyons on the oceanic islands of Hawaii. Mar. Ecol. 2010, 31, 183-199.

6. Drazen, J.C.; Goffredi, S.K.; Schlining, B.; Stakes, D.S. Aggregations of egg-brooding deep-sea fish and cephalopods on the Gorda Escarpment: a reproductive hot spot. Biol. Bul. 2003, 205, 1.

7. Ezer, T.; Heyman, W.D.; Houser, C.; Kjerfve, B. Modeling and observations of high-frequency flow variability and internal waves at a Caribbean reef spawning aggregation site. Ocean Dyn. 2010, 61(5), 1-18.

8. Riley, S.J.; DeGloria, S.D.; Elliot, R. A terrain ruggedness index that quantifies topographic heterogeneity. Intermt. J. sci. 1999, 5, 23-27.

9. Lundblad, E.; Miller, J.; Rooney, J.; Moews, M.; Chojnacki, J.; Weiss, J. Mapping Pacific Island Coral Reef Ecosystems with Multibeam and Optical Surveys. Coastal GeoTools. 2005.

10. Lundblad, E.; Wright, D.J.; Naar, D.F.; Donahue, B.T.; Miller, J.; Larkin, E.M.; Rinehart, R.W. Classifying benthic terrains with multibeam bathymetry, bathymetric position and rugosity: Tutuila, American Samoa. Mar. Geod. 2006, 29, 89-111.

11. Federal Geographic Data Committee, Standards Working Group Coastal and Marine Ecological Classification Standard Version 3.1 (Working Draft) NOAA Coastal Services Center, 2010.

12. Battista, T.A.; Costa, B.M.; Anderson, S.M. in NOAA Technical Memorandum NOS NCCOS 59, NOAA Center for Coastal Monitoring and Assessment, Biogeography Branch; Silver Spring: MD, 2007.

13. IPCC, Synthesis Report. Contribution of Working Groups I, II and III to the Fourth Assessment Report of the Intergovernmental Panel on Climate Change Geneva, Switzerland, 2007.

14. Amante, C.; Eakins, B.W. ETOPO1 1 Arc-Minute Global Relief Model: Procedures, Data Sources and Analysis. NOAA Technical Memorandum NESDIS NGDC-24, 2009, 19 pp. 